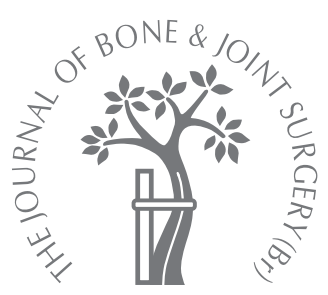

Y.-C. Lu, C.-H. Huang,

T.-K. Chang,

F.-Y. Ho,

C.-K. Cheng,

C.-H. Huang

From the Mackay

Memorial Hospital,

Taipei, Taiwan

\title{
Wear-pattern analysis in retrieved tibial inserts of mobile-bearing and fixed-bearing total knee prostheses
}

\begin{abstract}
Components from 73 failed knee replacements (TKRs) consisting of rotating-platform, mobile-bearing and fixed-bearing implants were examined to assess the patterns of wear. The patterns were divided into low-grade (burnishing, abrasion and cold flow) and highgrade (scratching, pitting/metal embedding and delamination) to assess the severity of the wear of polyethylene.

The rotating-platform group had a higher incidence of low-grade wear on the upper surface compared with the fixed-bearing group. By contrast, high-grade wear comprising scratching, pitting and third-body embedding was seen on the lower surface. Linear regression analysis showed a significant correlation of the wear scores between the upper and lower surfaces of the tibial insert $\left(R^{2}=0.29, p=0.04\right)$ for the rotating-platform group, but no significant correlation was found for the fixed-bearing counterpart.

This suggests that high-grade wear patterns on the upper surface are reduced with the rotating-platform design. However, the incidence of burnishing, pitting/third-body embedding and scratching wear patterns on the lower surface was higher compared with that in the fixed-bearing knee.
\end{abstract}

Analysis of wear of the articulating surface of ultrahigh-molecular-weight polyethylene (UHMWPE) from retrieved tibial components is an important method of assessing the clinical performance of total knee replacements (TKRs). ${ }^{1-5}$ Premature wear of UHMWPE tibial inserts is one of the major causes of failure of TKRs. ${ }^{6,7}$ Moreover, particulate wear debris released from polyethylene may also trigger a biological response resulting in osteolysis and/or aseptic loosening of the implant. ${ }^{8-12}$

The contemporary tibial component in a TKR can either be a fixed- or a mobilebearing design. The latter was introduced to provide congruity of the tibiofemoral articular surface and to allow relative movement between the lower surface of the polyethylene insert and the metal tibial baseplate for reduction of the constraint force. ${ }^{13,14}$ The contact stresses on the articular surface are theoretically reduced in mobile-bearing knees, thus potentially reducing the risk of polyethylene wear. These theoretical advantages have been evaluated in many biomechanical studies using experimental methods, ${ }^{15,16}$ or studies using numerical models such as finite-element analyses. ${ }^{17,18}$ Although these experimental approaches ${ }^{4,6,15-19}$ allow calculation of the distribution and magnitude of stress in order to predict the risk of UHMWPE wear, prediction of specific wear patterns such as pitting and delamination resulting from material fatigue or the pattern of scratching caused by third-body embedded debris may still be difficult. In this scenario wear analysis of the failed polyethylene inserts would give objective observation and information on varying types of wear pattern in different types of prosthesis.

The wear characteristics of the articular surface of tibial polyethylene inserts have been reported previously in a few retrieval studies. ${ }^{1,3,5,19-21}$ However, to the best of our knowledge, there has been no investigation of the relationship of the wear pattern of mobilebearing rotating-platform and fixed-bearing TKRs. From the biomechanical point of view, the mobile-bearing rotating-platform design can reduce the contact stress on the upper articular surface. However, it has an additional backside articulation. Our hypothesis was that this design may have less severe wear on the upper articular surface, but may produce unexpected wear on the lower surface. Our aim was to analyse the wear patterns on the upper and lower surfaces of tibial inserts retrieved from rotating-platform and fixedbearing polyethylene implants. 
Table I. Clinical details of the patients in the rotating-platform and fixed-bearing groups

\begin{tabular}{|c|c|c|c|c|c|c|}
\hline Design & Number & Female:male & $\begin{array}{l}\text { Mean (SD; range) age } \\
\text { at primary surgery (yrs) }\end{array}$ & $\begin{array}{l}\text { Mean (SD; range) } \\
\text { age at revision (yrs) }\end{array}$ & $\begin{array}{l}\text { Mean (SD; range) } \\
\text { body-weight (kg) }\end{array}$ & $\begin{array}{l}\text { Mean (SD; range) } \\
\text { length of implantation (mths) }\end{array}$ \\
\hline \multicolumn{7}{|c|}{ Rotating platform } \\
\hline LCS RP* & 15 & $11: 2$ & $58.5(7.4 ; 48.0$ to 73.0$)$ & $69(7.3 ; 59.0$ to 83.0$)$ & $72.8(7.3 ; 60.0$ to 87.0$)$ & $121(38.2 ; 48.0$ to 162.0$)$ \\
\hline \multicolumn{7}{|l|}{ Fixed-bearing } \\
\hline $\mathrm{PCA}^{\dagger}$ & 22 & $20: 2$ & $63.6(7.1 ; 49.0$ to 74.0$)$ & $73(7.6 ; 57.0$ to 81.0$)$ & $67.2(13.8 ; 45.0$ to 92.0$)$ & $93.6(39.6 ; 48.0$ to 180.0$)$ \\
\hline $\mathrm{MG}^{\ddagger}$ & 36 & $34: 1$ & $58.9(8.0 ; 40.0$ to 74.0$)$ & $67(8.1 ; 45.0$ to 81.0$)$ & $73.5(6.4 ; 64.0$ to 84.0$)$ & $109(31.3 ; 50.0$ to 156.0$)$ \\
\hline
\end{tabular}

Table II. Primary diagnoses and reasons for revision as reported by retrieving surgeons

\begin{tabular}{lccc}
\hline Diagnosis/reason for revision surgery & $\begin{array}{c}\text { Number of } \\
\text { rotating-platform }\end{array}$ & $\begin{array}{c}\text { Number of } \\
\text { Number of } \text { PCA }^{\dagger}\end{array}$ \\
\hline Failure of patellar component & 4 & 4 & 9 \\
Osteolysis/metallosis & 3 & 2 & 3 \\
Loosening/instability & 3 & 3 & 8 \\
Polyethylene wear & 1 & 7 & 11 \\
Infection & 1 & 2 & 1 \\
Pain & 2 & 3 & 2 \\
Others & 1 & 1 & 2 \\
Total $^{*}$ & 15 & 22 & 36 \\
\hline
\end{tabular}

* factors causing failure of the knee components such as a fall or ligamentous rupture are listed as other factors

† PCA, porous-coated anatomic

\section{Patients and Methods}

The components of 73 failed TKRs from 70 patients $(65$ women, 5 men; Table I) who underwent revision between 1997 and 2007 were retrieved. All the patients consented to the study which was approved by the hospital's institutional review board.

The retrieved components were subdivided into rotatingplatform and fixed-bearing groups. The former consisted of 15 knees with the low contact stress-rotating-platform prosthesis (LCS RP; DePuy, Warsaw, Indiana). There were 11 women and two men (one bilateral, one second revision due to instability) with a mean age at the time of revision of 69 (59.0 to 83.0). Knees with an LCS meniscal bearing tibial insert were excluded as this is a completely different type of insert making comparison difficult. None of the knees had breakage of the insert. The fixed-bearing group consisted of 22 knees with a Porous-Coated Anatomic prosthesis (PCA; Howmedica, Rutherford, New Jersey) and 36 with a MillerGalante prosthesis (MG; Zimmer). There were 54 women and three men (one bilateral) in this group with a mean age of 70 (45.0 to 81.0).

The mean length of implantation was 121 (48.0 to 162.0) for the rotating-platform knees, 93.6 (48.0 to 180.0) for the PCA knees and 109 (50.0 to 156.0) for the MG knees. The mean body-weight was $72.8 \mathrm{~kg}$ (60.0 to 87.0) for the patients with a rotating-platform knee, $67.2 \mathrm{~kg}$ (45.0 to 92.0) for those with a PCA knee, and $73.5 \mathrm{~kg}$
(64.0 to 84.0) for those with an MG knee. There was no significant difference ( $\mathrm{p}=0.6$, student $t$-test) in the bodyweight between the rotating-platform and fixed-bearing groups.

All the knees had primary osteoarthritis at the time of their initial TKR. The reasons for revision surgery are shown in Table II.

The rotating-platform prosthesis was a posteriorcruciate-ligament-sacrificing design and had a curve-oncurve design for the tibiofemoral articular surface. The fixed-bearing implant was a posterior-cruciate-ligamentretaining design and had a relatively non-conforming flaton-flat design for the tibiofemoral articular surface. All the inserts were made of UHMWPE. Based on the period in which the retrieved tibial inserts had been implanted, we were able to deduce that these components had been sterilised by gamma radiation in air. We did not obtain the dates of sterilisation from the manufacturers and thus could not provide the shelf-life data except for the mobile-bearing components in which the feedstock period was less than two years. All the retrieved femoral implants were made from cobalt-chrome alloy. The polyethylene inserts of the rotating-platform group were machined from polyethylene bar stock, which was ram-extruded using GUR 415 resin or 1050 resin. Dates of manufacture could not be determined for all the components, and therefore the specific resin designation for each insert could not be confirmed. For the 
Table III. Mean (SD; range) wear score on the upper surface for each wear pattern. The maximum score is 18 points

\begin{tabular}{|c|c|c|c|c|c|c|}
\hline \multirow[b]{2}{*}{ Designs } & \multicolumn{3}{|l|}{ Low-grade wear } & \multicolumn{3}{|l|}{ High-grade wear } \\
\hline & Burnishing & Abrasion & Cold flow & Scratching & $\begin{array}{l}\text { Pitting/metal } \\
\text { embedded }\end{array}$ & Delamination \\
\hline \multicolumn{7}{|c|}{ Rotating platform } \\
\hline LCS RP* & $5.3(4.7 ; 0.0$ to 18.0$)$ & $5.7(2.2 ; 1.0$ to 10.0$)$ & $1.2(1.8 ; 0.0$ to 6.0$)$ & $2.5(2.4 ; 0.0$ to 0.6$)$ & $6.6(2.9 ; 3.0$ to 12.0$)$ & $6.5(4.6 ; 0.0$ to 17.0$)$ \\
\hline \multicolumn{7}{|l|}{ Fixed-bearing } \\
\hline $\mathrm{PCA}^{\dagger}$ & $2.1(3.4 ; 0.0$ to 12.0$)$ & $7.4(1.8 ; 4.0$ to 10.0$)$ & $0.4(0.9 ; 0.0$ to 3.0$)$ & $5.2(2.4 ; 0.0$ to 10.0$)$ & $8.0(2.7 ; 2.0$ to 12.0$)$ & $11.7(5.1 ; 0.0$ to 18.0$)$ \\
\hline $\mathrm{MG}^{\ddagger}$ & $0.7(2.4 ; 0.0$ to 12.0$)$ & $3.9(4.5 ; 0.0$ to 13.0$)$ & $0.1(0.4 ; 0.0$ to 2.0$)$ & $3.8(4.0 ; 0.0$ to 11.0$)$ & $9.5(2.9 ; 3.0$ to 15.0$)$ & $8.1(5.0 ; 0.0$ to 16.0$)$ \\
\hline
\end{tabular}

PCA knee, the tibial insert was heat-treated. MG inserts were manufactured by direct compression molding. The mean thickness of the tibial insert was $11.5 \mathrm{~mm}(10.0$ to 17.5) for the rotating-platform knees, $11.3 \mathrm{~mm}$ (9.0 to 13.0) for the PCA knees and $10.2 \mathrm{~mm}$ (8.5 to 13.5$)$ for the MG knees. There was no statistically significant difference between the rotating-platform and the fixed-bearing groups in the thickness of the insert. The mediolateral width of the tibial insert ranged from $65 \mathrm{~mm}$ to $75 \mathrm{~mm}$ for the rotating-platfrom and from $58 \mathrm{~mm}$ to $77 \mathrm{~mm}$ for the fixed-bearing knees. Most of the patients had the standard regular size of tibial component. The mediolateral width of the tibial insert for the standard size was between $65 \mathrm{~mm}$ and $67 \mathrm{~mm}$ for both types of insert.

The wear patterns of the retrieved tibial inserts were analysed by stereomicroscopy (Leica MZ6; Leica Microsystems, Wetzlar, Germany) equipped with a digital image analysis system (Leica IM-1000; Leica Microsystems). The articulating surface wear score modified by Hood et $\mathrm{al}^{3}$ and Blunn et $\mathrm{al}^{1}$ was used to evaluate the surface wear. We recorded the wear pattern and score for each retrieved polyethylene component. This modified method of analysing the wear pattern and the scoring system have been established in our previous study, ${ }^{2}$ and is described as follows:

The different wear patterns include burnishing, abrasion, cold flow, scratching, pitting, metal embedding and delamination. Burnishing wear appears as a smooth or brightened surface without visible scratches, fracture or plastic deformation. Abrasion is low-stress wear which appears as a slight streak on the surface and can normally be observed only under the microscope. Cold flow shows plastic deformation without change in the volumetric loss of material. Scratching, however, appears as a substantial streak. Pitting usually causes a small cavity on the tibial insert. Metal embedding occurs when third bodies such as metal wear particles or chips from the femoral component embed into the polyethylene. Delamination appears as a subsurface crack and slice fracture of the material.

The wear score was calculated from the severity and area of wear. ${ }^{1,3,22}$ The scoring system was based on the worn area with a specific type of wear on the different zones of the tibial insert. The tibial articulating surface was divided into the medial and the lateral sides and each side was further divided into three equal zones anteroposteriorly. In order to quantify the worn area in each zone for different types of wear, a score of 0 to 3 was judged by two of the authors (FYH and TKC), who were blinded to the results. A score of 0 indicated no damage. Scores of 1, 2, and 3 indicated damage areas of $<10 \%, 10 \%$ to $50 \%$, and $>50 \%$ of the surface area, respectively. The total score for each type of wear was the sum of all the six zones.

The severity of wear of the inserts was assumed to correlate with the distribution of stress on the surfaces. ${ }^{22-25}$ The specific wear patterns were also expected to coincide with the levels of stress distribution. In order to distinguish between low-level and high-level wear, we divided the types of wear into two groups according to their mechanisms: low-grade (burnishing, abrasion and cold flow) and highgrade (scratching, pitting/metal embedding and delamination). Wear patterns and scores on the lower surfaces of the retrieved inserts were analysed by the same scoring system. Statistical analysis. Linear regression analysis was performed to determine if details such as the length of implantation and weight of the patient and the thickness of the original component were associated with the extent of wear (total wear scores) to either the upper or lower surface. Regression analysis was also used to assess whether the wear scores at the upper surface were associated with those of the lower surface.

The wear scores of the rotating-platform and fixedbearing groups were analysed by regression analysis and the analysis of variance (ANOVA) test using SPSS version 11.5 software (SPSS Inc., Chicago, Illinois). A p-value $\leq 0.05$ was considered to be significant.

\section{Results}

Wear patterns on the upper articular surface. High grade wear patterns of scratching, pitting/metal embedding and delamination were more commonly seen on the upper surface in the fixed-bearing group than in the rotating-platform group. However, there were no significant differences for each wear pattern between the two groups (Table III; Fig.1). Low-grade 


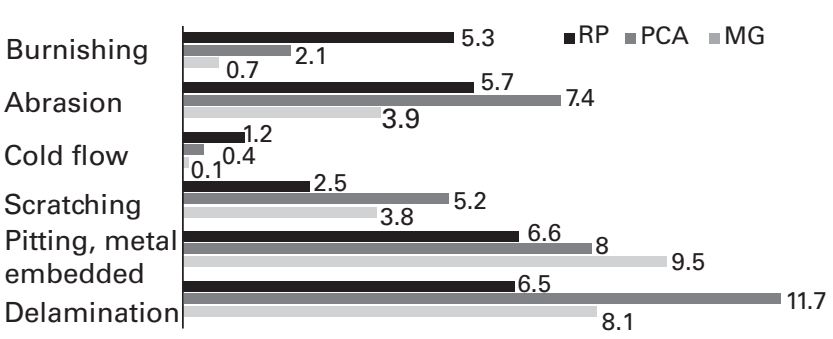

Fig. 1

Bar chart showing the mean wear score on the upper articular surface of the tibial insert for each wear pattern (RP, rotating-platform; PCA, porous-coated anatomic; MG, Miller-Galante).

wear patterns of burnishing, abrasion and cold flow were more common in the rotating-platform group than in the fixed-bearing group. The wear scores of the rotating-platform group for burnishing $(\mathrm{p}=0.002)$, and for cold flow $(\mathrm{p}=0.049)$ were significantly higher than those of the mobile bearing group. The total wear score of the upper articular surface was 108.6 for the rotating-platform group, which was significantly lower than that of the fixed-bearing group $(\mathrm{p}=0.002)(\mathrm{PCA}$, 160.9; MG 120.5).

Wear patterns on the lower surface. In contrast to the results seen on the upper articular surface, high-grade wear patterns were more commonly seen in the rotating-platform group (Fig. 2). The wear score on the lower surface of the rotating-platform group for scratching was significantly higher than those for the fixed-bearing group $(\mathrm{p}<0.001$; Table IV). As for pitting/embedding, the rotating-platform group was also significantly higher than those for the fixedbearing counterpart $(\mathrm{p}<0.001)$. Curvilinear scratching with a slight burnishing wear pattern was also observed (Fig. 3a) on the lower surface of the rotating-platform group, but not in the fixed-bearing group. However, lowgrade wear such as abrasion with slight pitting was more commonly seen in the fixed-bearing group (Table IV). The wear pattern was not significantly different in the two fixed-bearing designs (ANOVA test, $\mathrm{p}=0.297$ ) (Fig. 2). Protrusion of polyethylene into the screw holes and imprinting by the product marks of the base-plate were also

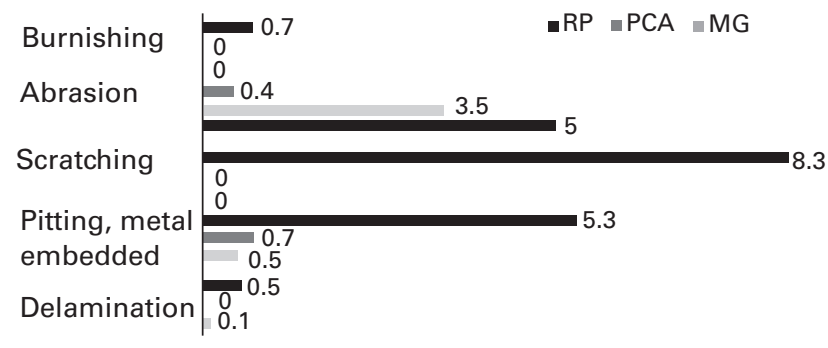

Fig. 2

Bar chart showing the mean wear score on the lower surface of the tibial insert for each wear pattern (RP, rotating-platform; PCA, porous-coated anatomic; MG, Miller-Galante).

observed in the fixed-bearing knees (Figs $3 \mathrm{~b}$ and $3 \mathrm{c}$ ). A severe wear pattern such as delamination was seen in very few cases on the lower surface of both groups and cold flow deformation was rarely seen.

Linear regression analysis (Table V) showed that there was a significant correlation between the damage score for the upper surface $\left(\mathrm{R}^{2}=0.12, \mathrm{p}=0.01\right)$ and the length of implantation time for all the retrievals (Fig. 4). A positive correlation was found for the fixed-bearing group when comparing the wear score for the upper surface with the implantation time $\left(\mathrm{PCA}, \mathrm{R}^{2}=0.4, \mathrm{p}=0.002\right.$; MG: $\mathrm{R}^{2}=0.17, \mathrm{p}=0.02$ ), this was not true for the rotating-platform group. However, no significant correlation was found when the wear score for the lower surface was compared with the length of implantation $\left(\mathrm{RP}, \mathrm{R}^{2}=0.13, \mathrm{p}=0.25\right.$; PCA, $\left.R^{2}=0.00, p=0.79 ; M G, R^{2}=0.02, p=0.40\right)$, or the body-weight $\left(\mathrm{RP}, \mathrm{R}^{2}=0.04, \mathrm{p}=0.54\right.$; PCA, $\mathrm{R}^{2}=0.00$, $\left.p=0.89 ; M G, R^{2}=0.00, p=0.92\right)$ for either group. There was no significant correlation between the polyethylene thickness and the upper $\left(\mathrm{RP}, \mathrm{R}^{2}=0.00, \mathrm{p}=0.97\right.$; PCA, $\left.\mathrm{R}^{2}=0.04, \mathrm{p}=0.40 ; \mathrm{MG}, \mathrm{R}^{2}=0.01, \mathrm{p}=0.75\right)$ or lower $(\mathrm{RP}$, $\mathrm{R}^{2}=0.00, \mathrm{p}=0.97 ;$ PCA, $\mathrm{R}^{2}=0.13, \mathrm{p}=0.11 ; \mathrm{MG}$, $\left.\mathrm{R}^{2}=0.06, \mathrm{p}=0.65\right)$ surface wear score. A negative correlation was found for all the retrieved specimens $\left(\mathrm{R}^{2}=0.04\right.$, $\mathrm{p}=0.09$ ) when independently comparing the wear scores for the lower surface with the thickness of the insert, but this was not statistically significant. In addition, we further

Table IV. The mean (SD, range) score on the lower surface for each wear pattern. The maximum score is 18 points

\begin{tabular}{|c|c|c|c|c|c|c|}
\hline \multirow[b]{2}{*}{ Design } & \multicolumn{3}{|l|}{ Low-grade wear } & \multicolumn{3}{|l|}{ High-grade wear } \\
\hline & Burnishing & Abrasion & Cold flow & Scratching & $\begin{array}{l}\text { Pitting/metal } \\
\text { embedded }\end{array}$ & Delamination \\
\hline \multicolumn{7}{|c|}{ Rotating platform } \\
\hline LCS RP* & $0.7(2.6 ; 0.0$ to 9.0$)$ & $0.4(1.0 ; 0.0$ to 3.0$)$ & - & $8.3(3.2 ; 5.0$ to 14.0$)$ & $5.3(2.3 ; 2.0$ to 9.0$)$ & $0.5(0.8 ; 0.0$ to 2.0$)$ \\
\hline \multicolumn{7}{|c|}{ Fixed-bearing } \\
\hline $\mathrm{PCA}^{\dagger}$ & 0.0 & $3.5(4.2 ; 0.0$ to 13.0$)$ & - & 0.0 & $0.7(2.7 ; 0.0$ to 12.0$)$ & 0.0 \\
\hline $\mathrm{MG}^{\ddagger}$ & 0.0 & $5.0(2.8 ; 0.0$ to 12.0$)$ & - & 0.0 & $0.5(1.0 ; 0.0$ to 3.0$)$ & $0.1(0.4 ; 0.0$ to 2.0$)$ \\
\hline
\end{tabular}




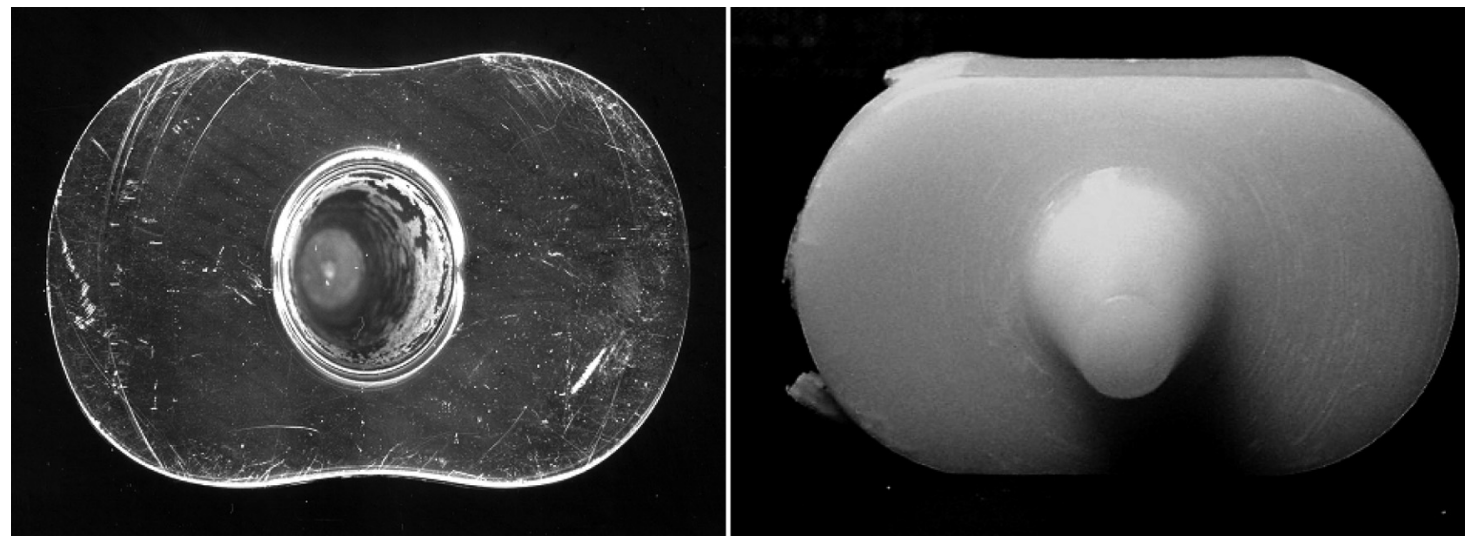

Fig. 3a


Fig. $3 b$
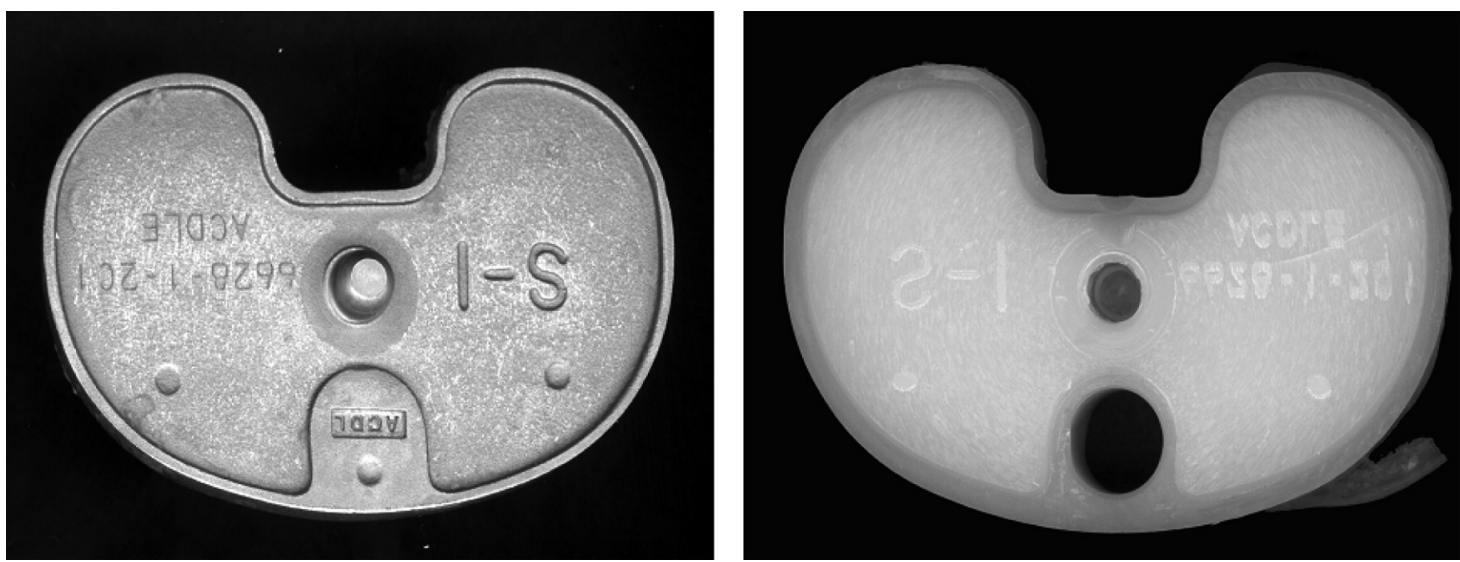

Fig. 3c

Photographs showing the lower surface of a) mobile-bearing rotating-platform; b) fixed-bearing Miller-Galante and c) porouscoated anatomic (PCA) fixed-bearing knee prostheses.

analysed the correlation of the wear score of the upper and lower surfaces. There was a significant correlation $\left(\mathrm{R}^{2}=0.29, \mathrm{p}=0.04\right)$ for the rotating-platform group (Fig. 4b), but not for the fixed-bearing group (PCA, $\left.\mathrm{R}^{2}=0.02, \mathrm{p}>0.05 ; \mathrm{MG}, \mathrm{R}^{2}=0.001, \mathrm{p}>0.05\right)$.

\section{Discussion}

The extent of polyethylene wear in modular TKRs is dependent on a number of factors, which include the design of the articular surface, the material used, the kinematics of the joint, the method of sterilisation and the 
Table V. Correlation results $\left(\mathrm{R}^{2}, \mathrm{p}\right.$-value): total wear scores (including upper and lower surfaces) versus clinical variables

\begin{tabular}{|c|c|c|c|c|c|c|c|c|}
\hline \multirow[b]{2}{*}{ Variable } & \multicolumn{2}{|c|}{ Total retrievals (scores) } & \multicolumn{2}{|c|}{ Rotating-platform (scores) } & \multicolumn{2}{|c|}{ PCA $^{*}$ (scores) } & \multicolumn{2}{|c|}{ Miller-Galante (scores) } \\
\hline & Upper & Lower & Upper & Lower & Upper & Lower & Upper & Lower \\
\hline Time of implantation & $\begin{array}{l}R^{2}=0.12 \\
p=0.01\end{array}$ & $\begin{array}{l}R^{2}=0.01 \\
p=0.50\end{array}$ & $\begin{array}{l}R^{2}=0.09 \\
p=0.78\end{array}$ & $\begin{array}{l}R^{2}=0.13 \\
p=0.25\end{array}$ & $\begin{array}{l}R^{2}=0.41 \\
p=0.002\end{array}$ & $\begin{array}{l}R^{2}=0.00 \\
p=0.79\end{array}$ & $\begin{array}{l}R^{2}=0.17 \\
p=0.02\end{array}$ & $\begin{array}{l}\mathrm{R}^{2}=0.02 \\
\mathrm{p}=0.4\end{array}$ \\
\hline Body-weight & $\begin{array}{l}R^{2}=0.00 \\
p=0.96\end{array}$ & $\begin{array}{l}R^{2}=0.01 \\
p=0.53\end{array}$ & $\begin{array}{l}R^{2}=0.00 \\
p=0.94\end{array}$ & $\begin{array}{l}R^{2}=0.04 \\
p=0.54\end{array}$ & $\begin{array}{l}R^{2}=0.00 \\
p=0.92\end{array}$ & $\begin{array}{l}R^{2}=0.00 \\
p=0.89\end{array}$ & $\begin{array}{l}\mathrm{R}^{2}=0.01 \\
\mathrm{p}=0.71\end{array}$ & $\begin{array}{l}\mathrm{R}^{2}=0.00 \\
\mathrm{p}=0.9\end{array}$ \\
\hline Insert thickness & $\begin{array}{l}\mathrm{R}^{2}=0.01 \\
\mathrm{p}=0.47\end{array}$ & $\begin{array}{l}R^{2}=0.04 \\
p=0.09\end{array}$ & $\begin{array}{l}\mathrm{R}^{2}=0.00 \\
\mathrm{p}=0.97\end{array}$ & $\begin{array}{l}\mathrm{R}^{2}=0.00 \\
\mathrm{p}=0.97\end{array}$ & $\begin{array}{l}\mathrm{R}^{2}=0.04 \\
\mathrm{p}=0.40\end{array}$ & $\begin{array}{l}\mathrm{R}^{2}=0.13 \\
\mathrm{p}=0.11\end{array}$ & $\begin{array}{l}\mathrm{R}^{2}=0.01 \\
\mathrm{p}=0.75\end{array}$ & $\begin{array}{l}\mathrm{R}^{2}=0.06 \\
\mathrm{p}=0.6\end{array}$ \\
\hline
\end{tabular}

* PCA, porous-coated anatomic

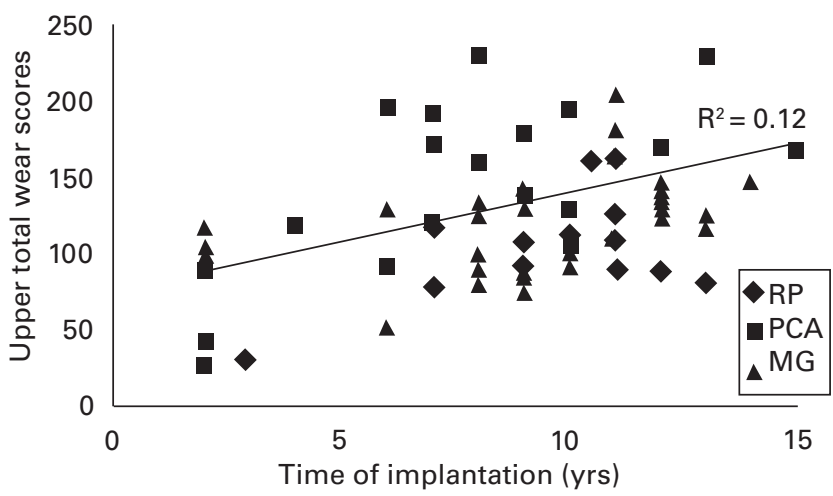

Fig. 4a

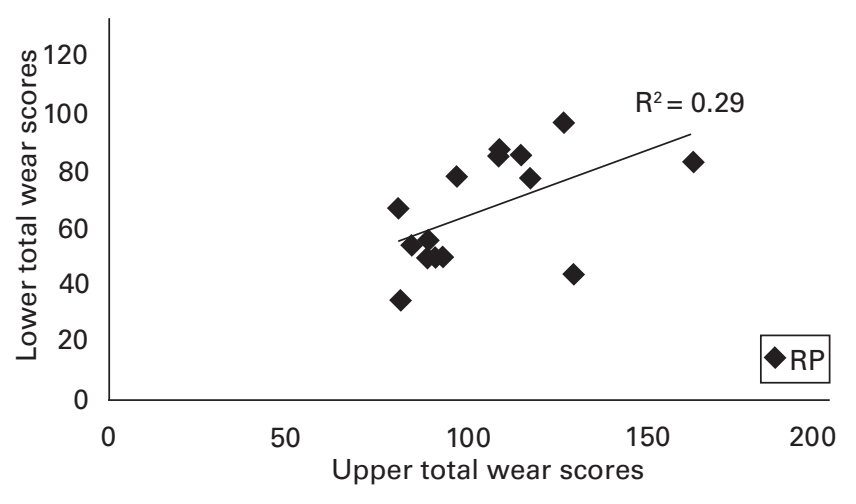

Fig. $4 b$

Scattergram showing a) the upper surface wear score versus the length of implantation time $\left(R^{2}=0.12, p=0.01\right)$ for all retrieved specimens and b) the upper surface wear score versus the lower surface wear score for the rotating-platform group $\left(R^{2}=0.29, p=0.04\right)(R P$, rotating-platform; PCA, porous-coated anatomic; MG, Miller-Galante).

design. ${ }^{17,20,23,26,27}$ Although these variables are critical, another site of polyethylene wear is the lower surface of the insert. 28

Polyethylene wear on the upper surface of the tibial insert has been described in many biomechanical studies ${ }^{15,16,18,23,29}$ and well-recognised in many retrieval studies. ${ }^{2,21,22,30}$ Most of the results from these studies show that a high conforming design reduces the contact stress and thus lowers UHMWPE fatigue and wear. However, there have been few studies which have examined wear pat- terns on the lower surface. A highly conforming articular surface with a moveable tibial insert in the rotating-platform design has given rise to the question of whether this design actually provides better wear resistance 31,32 than the fixed-bearing design. This issue, however, may be considered as a trade-off effect. Our results support the hypothesis that polyethylene wear on the upper surface is reduced with the rotating-platform design, but there is also a higher incidence of high-grade wear patterns on the unconstrained lower surface.

Wear patterns on the upper surface. On the upper surface, high-grade wear patterns of delamination, pitting and scratching were seen more often in the fixed-bearing than in rotating-platform knees $(\mathrm{p}<0.05)$. In contrast to the fixedbearing knees, low-grade wear patterns of burnishing and cold flow were generally seen on the rotating-platform knees. This low-grade wear has been reported previously. ${ }^{15,16,18,23}$ Burnishing wear could be attributed to the highly conforming design and consequent reduction in polyethylene wear. The cold flow often seen in the rotatingplatform group was considered to result from the lack of a boundary constraint of the tibial baseplate. In addition to conforming geometry, the kinematics of the tibial bearing also influence the wear pattern. ${ }^{27}$ Wear in the rotatingplatform knee is theoretically reduced because the rolling/ sliding curvilinear movement is separated from the transverse axial rotation movement on two separate articulating surfaces. This eliminates the cross-paths which cause higher wear in polyethylene as compared with the reciprocal linear or curvilinear paths. ${ }^{27,30}$ As for the non-conforming surface design of the fixed-bearing knee, the upper surface is required to accommodate all of the knee movements leading to multidirectional shear and high contact stresses on the surface of the polyethylene with the potential of severe or asymetrical wear patterns. ${ }^{2}$ Lower rates of wear on the upper surface of the mobile knees may be explained by the decoupling of the rotational or translational movements which decrease the amount of multidirectional sliding as compared with the fixed-bearing knees.

Wear patterns on the lower surface. Although the rotatingplatform group showed better wear resistance on the upper surface, wear patterns such as burnishing, scratching and pitting/third-body embedding were commonly seen on the lower surface. The rotating-platform metal baseplate which 
has a polished surface (mean roughness value $(\mathrm{Ra})$ ranging from $0.01 \mu \mathrm{m}$ to $0.04 \mu \mathrm{m}$; mean scratch height $(\mathrm{Rp})$ ranging from $0.05 \mu \mathrm{m}$ to $0.14 \mu \mathrm{m}),{ }^{33}$ showed scratching patterns on the lower surface of the polyethylene and the upper surface of the baseplate (Fig. 3). The scratching pattern on the lower surface of the insert was curvilinear and possibly caused by the rotational movement against the baseplate. The rotating-platform design introduces an additional surface and also allows for third-body debris to invade this interface which could be further susceptible to wear. Similar wear patterns were also reported from previous retrieval studies. $^{21,34,35}$

Our results showed a positive correlation for the rotatingplatform group when we compared the wear score of the upper surface with that of the lower surface $\left(\mathrm{R}^{2}=0.29\right.$, $\mathrm{p}=0.04$; Fig. 4b). However, there was no statistical correlation for the fixed-bearing group. A similar trend was reported by Garcia et al. ${ }^{21}$ They concluded that higher levels of wear on the upper surface were found to be associated with higher levels of wear on the lower surface $\left(\mathrm{R}^{2}=0.25\right.$, $\mathrm{p}<0.001)$. This finding allows us to speculate that the amount of movement of the insert contributes to the wear on the lower surface.

As for the fixed-bearing group, although some abrasion, pitting and embedded debris were evident, high-grade wear patterns such as scratching and delamination were less frequent on the lower surface. Wear patterns in the fixed-bearing group were similar and showed slight abrasion which was likely to be related to the texture of the metal surface. Protrusion of polyethylene into the screw holes and imprints by the marks or lettering of the base-plate were visible on the lower surface of the inserts, leading to the supposition that there may be relative movement taking place at this interface. Furthermore, embedded debris was seen on the lower surface of the inserts in the fixed-bearing group.

Different wear patterns observed in the rotating-platform and the fixed-bearing knees are related to their clinical performance. For the highly conforming design of the rotatingplatform knee, a higher incidence of burnishing and abrasion wear patterns was commonly generated on the articular surfaces, and the wear patterns are likely to produce a large amount of smaller and granular particles ${ }^{36}$ triggering a biological response ${ }^{10}$ and inducing osteolysis. ${ }^{11}$ With regard to the non-conforming design of the fixed-bearing knees, highgrade patterns of delamination, pitting and scratching commonly observed on the upper surface of the tibial insert produce larger shred particles or large volumetric loss of material. ${ }^{36}$ Although the prevalence of osteolysis in the fixed-bearing knees has been shown to be lower than in the rotating-platform knees, ${ }^{11}$ more severe polyethylene wear (delamination) on the upper surface could result in deformity, instability and failure of the TKRs.

The use of either a fixed or a mobile bearing is still controversial. ${ }^{37}$ Well-designed fixed-bearing TKRs seem to give excellent results equivalent to those of the mobile-bearing designs. ${ }^{38-40}$ Although the biomechanical benefit of the rotating-platform knee is attractive, its clinical performance has yet to be proved. Modularity of the tibial component affords various options at the time of surgery, but the additional interface between a tibial insert and the baseplate creates an unintentional bearing surface. Micromovement at this interface is inevitable even for the fixed-bearing design and backside wear can be correlated with at this site. $^{28,41}$ Therefore, modification of the locking mechanism for fixed-bearing knees to reduce micromovement or to create a new mechanism for mobile-bearing knees in order to inhibit the foreign particles from intruding into the interface is likely to be beneficial. The use of an all-polyethylene tibial component ${ }^{42}$ combined with moderate conformity without abrupt changes in tibiofemoral articular surface ${ }^{1}$ is further recommended for a primary TKR.

Our study has many limitations. First, the wear scores were graded from a visual scaling method, and this method can only assess patterns in a two-dimensional manner. ${ }^{3,43} \mathrm{It}$ is difficult to measure the volumetric loss of material of the tibial insert. We did not measure the benefit of reduced volumetric wear in the mobile-bearing tibial inserts. Moreover, there are different wear patterns in the same worn region of the polyethylene. It is not easy to identify more than two types of wear pattern in one region. Analysis of the wear pattern was carried out by two independent observers to ensure repeatability and consistency.

Secondly, most of the primary TKRs were not performed at the authors' institute and many were carried out several years ago. It was therefore difficult to acquire the manufacturing information for the polyethylene relating to surface roughness, sterilisation technique, shelf life and storage data.

Finally, wear patterns observed in our study were limited to three designs of knee and therefore they could not represent all the design features of contemporary knee prostheses. The heat treatment of the articulating surface of the PCA inserts may contribute to a more severe wear pattern and earlier revision, i.e. higher scores, as seen in our series. ${ }^{1,22}$ Nevertheless, we believe that our study provides valuable information about the clinical performance of TKRs and describes different wear patterns between the rotating-platform and the fixed-bearing designs.

The wear of UHMWPE in our study supports our hypothesis that the mobile-bearing rotating-platform provides an advantage in reducing high-grade wear patterns of scratching, pitting and delamination on the upper surface in comparison with the fixed-bearing group. A mobilebearing knee also generates wear patterns such as burnishing, pitting/third body embedding and scratching on the lower surface. The superiority of long-term performance requires further verification.

We acknowledge the financial support of the National Science Council (NSC 94 2213-E-195-001, NSC 96-2314-B-195-007-MY3), the Ministry of Economic Affairs, ROC (97-EC-17-A-19-S1-027), and experimental support by the Electron Microscope Laboratory of Mackay Memorial Hospital.

No benefits in any form have been received or will be received from a commercial party related directly or indirectly to the subject of this article. 


\section{References}

1. Blunn GW, Joshi AB, Minns RJ, et al. Wear in retrieved condylar knee arthroplasties: a comparison of wear in different designs of 280 retrieved condylar knee prostheses. $J$ Arthroplasty 1997;12:281-90.

2. Ho FY, Ma HM, Liau JJ, Yeh CR, Huang CH. Mobile-bearing knees reduce rotational asymmetric wear. Clin Orthop 2007;462:143-9.

3. Hood RW, Wright TM, Burstein AH. Retrieval analysis of total knee prostheses: a method and its application to 48 total condylar prostheses. J Biomed Mater Res 1983;17:829-42.

4. Rose RM, Nusbaum HJ, Schneider H, et al. On the true wear rate of ultra high-molecular-weight polyethylene in the total hip prosthesis. J Bone Joint Surg [Am] 1980;62A:537-49.

5. Wright TM, Rimnac CM, Stulberg SD, et al. Wear of polyethylene in total joint replacements: observations from retrieved PCA knee implants. Clin Orthop 1992;276:126-34.

6. Wright T, Bartel DL. The problem of surface damage in polyethylene total knee components. Clin Orthop 1986;205:67-74.

7. Reay E, Wu J, Holland J, Deehan D. Premature failure of Kinemax Plus knee replacements. J Bone Joint Surg [Br] 2009;91-B:604-11.

8. Goodman S, Lidgren L. Polyethylene wear in knee arthroplasty: a review. Acta Orthop Scand 1992;63:358-64

9. Sacomen D, Smith RL, Song Y, Fornasier V, Goodman SB. Effects of polyethylene particles on tissue surrounding knee arthroplasties in rabbits. J Biomed Mater Res 1998;43:123-30.

10. Shanbhag AS, Jacobs JJ, Black J, Galante J0, Glant TT. Macrophage/particle interactions: effect of size, composition and surface area. J Biomed Mater Res 1994;28:81-90.

11. Huang CH, Ma HM, Liau JJ, Ho FY, Cheng CK. Osteolysis in failed total knee arthroplasty: a comparison of mobile-bearing and fixed-bearing knees. J Bone Joint Surg [Am] 2002;84-A:2224-9.

12. Peters PC Jr, Engh GA, Dwyer KA, Vinh TN. Osteolysis after total knee arthroplasty without cement. J Bone Joint Surg [Am] 1992;74-A:864-76.

13. Goodfellow JW, O'Connor J. Clinical results of the Oxford knee: surface arthroplasty of the tibiofemoral joint with a meniscal bearing prosthesis. Clin Orthop 1986;205:21-42

14. Buechel FF, Pappas MJ. New Jersey low contact stress knee replacement system: ten-year evaluation of meniscal bearings. Orthop Clin North Am 1989;20:14777.

15. Cheng CK, Huang $\mathbf{C H}$, Liau JJ. The influence of surgical malalignment on the contact pressure of fixed and mobile bearing knee prostheses: a biomechanical study. Clin Biomech (Bristol, Avon) 2003;18:231-6.

16. Matsuda S, White SE, Williams VG 2nd, McCarthy DS, Whiteside LA. Contact stress analysis in meniscal bearing total knee arthroplasty. J Arthroplasty 1998;13:699-706.

17. Shi JF, Wang CJ, Berryman F, Hart W. The effect of polyethylene thickness in fixed- and mobile-bearing total knee replacements. Proc Inst Mech Eng [H] 2008;222:657-67.

18. Liau JJ, Cheng CK, Huang CH, Lo WH. The effect of malalignment on stresses in polyethylene component of total knee prostheses: a finite element analysis. Clin Biomech \{Bristol, Avon) 2002;17:140-6.

19. Wasielewski RC, Galante J0, Leighty RM, Natarajan RN, Rosenberg AG Wear patterns on retrieved polyethylene tibial inserts and their relationship to technical considerations during total knee arthroplasty. Clin Orthop 1994;299:31 43.

20. Tanner MG, Whiteside LA, White SE. Effect of polyethylene quality on wear in total knee arthroplasty. Clin Orthop 1995;317:83-8.

21. Garcia RM, Kraay MJ, Messerschmitt PJ, Goldberg VM, Rimnac CM. Analysis of retrieved ultra-high-molecular-weight polyethylene tibial components from rotating-platform total knee arthroplasty. J Arthroplasty 2009;24:131-8.
22. Collier JP, Mayor MB, McNamara JL, Surprenant VA, Jensen RE. Analysis of the failure of 122 polyethylene inserts from uncemented tibial knee components. Clin Orthop 1991;273:232-42.

23. Bartel DL, Bicknell VL, Wright TM. The effect of conformity, thickness, and material on stresses in ultra-high molecular weight components for total joint replacement. J Bone Joint Surg [Am] 1986;68-A:1041-51.

24. Rawlinson JJ, Furman BD, Li S, Wright TM, Bartel DL. Retrieval, experimental, and computational assessment of the performance of total knee replacements. J Orthop Res 2006;24:1384-94.

25. Bartel DL, Rawlinson JJ, Burstein AH, Ranawat CS, Flynn WF Jr. Stresses in polyethylene components of contemporary total knee replacements. Clin Orthop 1995;817:7682.

26. Lombardi AV Jr, Ellison BS, Berend KR. Polyethylene wear is influenced by manufacturing technique in modular TKA. Clin Orthop 2008;466:2798-805.

27. McEwen HM, Barnett PI, Bell CJ, et al. The influence of design, materials and kinematics on the in vitro wear of total knee replacements. J Biomech 2005;38:357-65.

28. Surace MF, Berzins A, Urban RM, et al. Backsurface wear and deformation in polyethylene tibial inserts retrieved postmortem. Clin Orthop 2004;404:14-23.

29. Huang $\mathbf{C H}$, Liau JJ, Huang $\mathbf{C H}$, Cheng $\mathbf{C K}$. Stress analysis of the anterior tibial post in posterior stabilized knee prostheses. J Orthop Res 2007;25:442-9.

30. Kop AM, Swarts E. Quantification of polyethylene degradation in mobile bearing knees: a retrieval analysis of the Anterior-Posterior-Glide (APG) and Rotating Platform (RP) low contact stress (LCS) knee. Acta Orthop 2007;78:364-70.

31. Grupp TM, Kaddick C, Schwiesau J, Maas A, Stulberg SD. Fixed and mobile bearing total knee arthroplasty: influence on wear generation, corresponding wear areas, knee kinematics and particle composition. Clin Biomech (Bristol, Avon)2009;24:210-17.

32. Haider H, Garvin K. Rotating platform versus fixed-bearing total knees: an in vitro study of wear. Clin Orthop 2008;466:2677-85.

33. Chapman-Sheath P, Cain S, Bruce WJ, Chung WK, Walsh WR. Surface roughness of the proximal and distal bearing surface of mobile bearing total knee prostheses. $J$ Arthroplasty 2002;17:713-17.

34. Jones VC, Williams IR, Auger DD, et al. Quantification of third body damage to the tibial counterface in mobile bearing knees. Proc Inst Mech Eng [H]2001;215:171-9.

35. Atwood SA, Currier JH, Mayor MB, et al. Clinical wear measurement on low contact stress rotating platform knee bearings. J Arthroplasty 2008;23:431-40.

36. Huang $\mathbf{C H}$, Ho FY, Ma HM, et al. Particle size and morphology of UHMWPE wear debris in failed total knee arthroplasties: a comparison between mobile bearing and fixed bearing knees. J Orthop Res 2002;20:1038-41.

37. Huang CH, Liau JJ, Cheng CK. Fixed or mobile-bearing total knee arthroplasty. J Orthop Surg 2007;2:1.

38. Wylde V, Learmonth I, Potter A, Bettinson K, Lingard E. Patient-reported outcomes after fixed-versus mobile-bearing total knee replacement: a multi-centre randomised controlled trial using the Kinemax total knee replacement. J Bone Joint Surg [Br] 2008;90B:1172-9.

39. Oh KJ, Pandher DS, Lee SH, Sung Joon SD Jr, Lee ST. Meta-analysis comparing outcomes of fixed-bearing and mobile-bearing prostheses in total knee arthroplasty. J Arthroplasty 2009;24:873-84.

40. Kim YH, Kim DY, Kim JS. Simultaneous mobile- and fixed-bearing total knee replacement in the same patients: a prospective comparison of mid-term outcomes using a similar design of prosthesis. J Bone Joint Surg [Br] 2007;89-B:904-10.

41. Rao AR, Engh GA, Collier MB, Lounici S. Tibial interface wear in retrieved total knee components and correlations with modular insert motion. J Bone Joint Surg [Am]2002;84A:1849-55.

42. Ma HM, Lu YC, Ho FY, Huang CH. Long-term results of total condylar knee arthroplasty. J Arthroplasty 2005;20:580-4.

43. Engh GA, Zimmerman RL, Parks NL, Engh CA. Analysis of wear in retrieved mobile and fixed bearing knee inserts. J Arthroplasty 2009;24 (6 Suppl):28-32. 